\title{
Outcomes of reoperations after Ross procedure
}

\author{
Paul Stelzer, Javier Mejia, Elbert Eugene Williams \\ Department of Cardiovascular Surgery, Icahn School of Medicine at Mount Sinai, New York, NY, USA \\ Correspondence to: Paul Stelzer. 1190 Fifth Avenue, Guggenheim Pavilion-Two West, New York, NY 10029, USA. \\ Email: paul.stelzer@mountsinai.org.
}

\begin{abstract}
Background: Potential for difficult reoperations has been a concern for patients undergoing a Ross procedure. Data regarding the outcomes of such reoperations is extremely limited. We examined our experience to define the current scope and risk of these operations.

Methods: Between 1996 and 2020,83 patients who had a previous Ross procedure underwent 89 reoperative surgeries. There were 72 males and average age was 48 with a range of 18-76. Twenty-four patients had more than one prior reoperation, with five patients having more than one reoperation post Ross. Patients were stratified by primary reason for reoperation including autograft dysfunction, homograft dysfunction, or other cardiac surgical problems. Demographic, operative, and outcomes data were collected from clinical records and placed in a secure data base for analysis.

Results: A total of 176 procedures were done in the 89 operations. Autograft dysfunction affected 68 patients. Homograft dysfunction affected 27 patients. Both of these were seen in 17 patients. Other cardiac problems required 79 other procedures. There were two $(2.2 \%)$ operative deaths, with perioperative morbidity affecting six patients (6.7\%). Survival following reoperation after Ross was $82.3 \%$ and $77.5 \%( \pm 2)$, at ten and fifteen years respectively.

Conclusions: Reoperations after a Ross procedure can be challenging but can be done with a high degree of safety and long-term benefit in experienced hands.
\end{abstract}

Keywords: Ross procedure; pulmonary autograft; aortic root replacement; reoperation; valve surgery

Submitted Apr 26, 2021. Accepted for publication Jul 02, 2021.

doi: 10.21037/acs-2021-rp-29

View this article at: https://dx.doi.org/10.21037/acs-2021-rp-29

\section{Introduction}

Not since 2010 has there been a large series of patients reported having repeat surgery after a Ross procedure. The magnitude of risk at these re-interventions has been regarded as a reason not to do the Ross in the first place. We sought to re-examine this question with an additional decade of perspective by looking at our experience over the last twentyfive years.

\section{Methods}

\section{Patients \& study design}

We retrospectively identified 83 patients who had 89 reoperations after a prior Ross procedure. Our Institutional Review
Board (IRB)-approved Ross database was updated with recent clinical follow-up and used as the primary source of the data with waiver of individual consent. Survival was determined at last medical contact which is part of the database. This included appointments, patient call-ups, or contact with the patient's family physician/cardiologist. Mean duration of time since original Ross operation was 12.6 years $( \pm 6.9)$ (Table 1). Mean duration of clinical follow-up was 7.1 years $( \pm 5.4$; 560 total patient-years) following reoperation, with follow-up data beyond the one-month perioperative period on 78 out of 83 patients. Operative interventions on both aortic and pulmonary valves/roots were included as well as any other open cardiac operations for the ascending aorta, coronaries, atrio-ventricular valves, or atrial fibrillation. Percutaneous interventions were not included. 


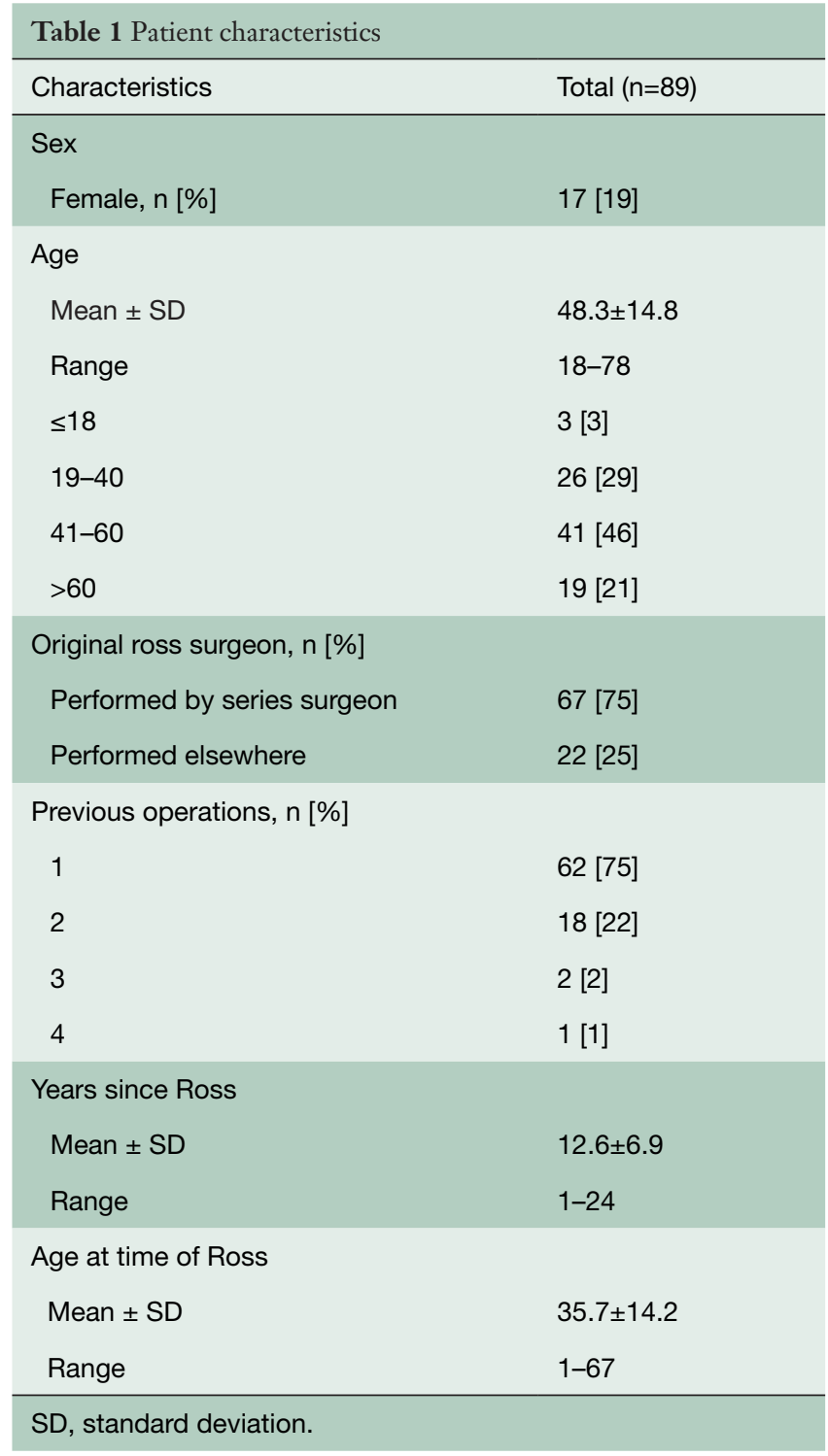

\section{Statistical analysis}

As this was a single-surgeon case series, no sample size or statistical calculations were performed in order to compare the perioperative data. Data were reported via a secure database through descriptive statistics, with no hypothesis testing. Ordinal and nominal data were expressed as absolute and relative frequencies. Continuous data were presented as mean \pm standard deviation. Perioperative mortality and morbidity data were tracked at postoperative follow-up appointments routinely scheduled at $>30$ days after operation.

Survival analysis was performed for the primary outcome of mortality following reoperation via the Kaplan-Meier method. Curves were designed for total survival after original Ross procedure (including after reoperation), as well as for survival exclusively following reoperation. Confidence intervals of $95 \%$ were represented for both Kaplan-Meir curves. Individual patients, regardless of number of reoperations, were counted only once toward overall long-term survival after the Ross. Similarly, individual patients were counted only once toward survival following their first reoperation.

\section{Results}

There were 176 specific procedures done including autograft [68], homograft [27], ascending aorta [16], mitral [24], tricuspid [20], coronary [5], and ablation of atrial fibrillation [14] procedures (Table 2). Perioperative mortality was $2.2 \%$ $(\mathrm{n}=2)$ (Table 3). After reoperation to replace a stenotic mitral valve, one patient developed severe pulmonary edema despite normal ventricular function and low pulmonary artery pressures. He was rescued with extracorporeal membrane oxygenation (ECMO). Bleeding required wash-out after three days and weaning after five days was unsuccessful. Multiorgan failure expanded to include renal failure and then liver which led to refractory acidosis and withdrawal of care on post-operative day fourteen. The other mortality occurred in a patient with severe left ventricular enlargement $(8.4 / 6.5 \mathrm{~cm})$ with an ejection fraction (EF) $40 \%$ who had both roots rereplaced, tricuspid repair and Maze with very long clamp and pump times. He did well for thirty-six hours but then developed catastrophic sepsis and respiratory failure due to pseudomonas pneumonia. He went on to renal failure requiring dialysis and probable heparin induced thrombocytopenia with extensive lower extremity tissue necrosis threatening limb loss that led family to withdraw care ten days after surgery.

Perioperative morbidity affected six other patients (6.7\%). Morbidities included bleeding requiring re-exploration, tracheostomy for respiratory failure, renal failure requiring dialysis, cerebrovascular accident, and permanent pacemaker (Table 3). Not included was one patient who had an unusual and late case of upper sternal infection that required drainage and reconstruction eleven months after surgery. Transfusion of blood or blood products was required in only twenty-five (28\%) of the cases (Table 2).

\section{Survival outcomes}

Mean time to reoperation following Ross procedure was 


\begin{tabular}{ll} 
Table 2 Operative characteristics and outcomes \\
\hline Characteristics & Total $(\mathrm{n}=89)$ \\
\hline Ross-related procedures & \\
$\mathrm{n}$ & 95 \\
Autograft & 68 \\
Homograft & 27 \\
Combined & 17 \\
Other cardiac surgery & \\
$\mathrm{n}$ & 79 \\
Aortic & 16 \\
CABG & 5 \\
Mitral & 24 \\
Tricuspid & 20 \\
Arrhythmia & 14 \\
Cardiopulmonary bypass time (minutes) & \\
Mean \pm SD & $209.3 \pm 81.2$ \\
Range & $71-443$ \\
Cross clamp time (minutes) & \\
\hline Mean \pm SD & $37-358$ \\
Range & \\
\hline Patients receiving transfusions & \\
\hline b & \\
\hline
\end{tabular}

${ }^{a}$ Not including four patients operated on without cross clamping; ${ }^{b} 55$ patients received autologous blood transfusion.
$12.6( \pm 6.9)$ years. Survival exclusively following reoperation after Ross was $94.6 \%(86.1-97.9 \%)$ at one year, $87.4 \%$ (76.2-93.6\%) at five years, $82.3 \%(68.9-90.4 \%)$ at ten years, and $77.5 \%(60.4-87.9 \%)$ at fifteen years (Figure $1 A)$. Overall survival following Ross procedure was $98.6 \%$ (CI 90.399.8\%) at ten years, 90.5\% (CI 79.9-95.6\%) at fifteen years, and $82.1 \%$ (CI 69.0-90.1\%) at twenty years (Figure 1B).

\section{Discussion}

There has long been a very limited use of the Ross procedure for young patients with irreparable aortic valve disease. In addition to the technical complexity of the operation, the potential need for difficult reoperation(s) has been regarded as a reason not to do the Ross in the first place (1). On the other hand, the Ross has been shown to have a long-term survival advantage over alternatives such as mechanical and tissue valve replacement (2-4). Because of this, we anticipate that there will be an increasing number of Ross patients at risk for additional surgery in their lifetime. Data are needed to reassure those patients and their doctors that redo surgery after a Ross can be done safely and can keep these patients on track to live long and productive lives.

A number of reports have described good results of valvesparing surgery to rescue a failing pulmonary autograft (5-7). The most recent looked at 86 European patients with only $1 \%$ mortality (8). Autograft repair, however, is not always possible which implies a selection bias in these studies. Our

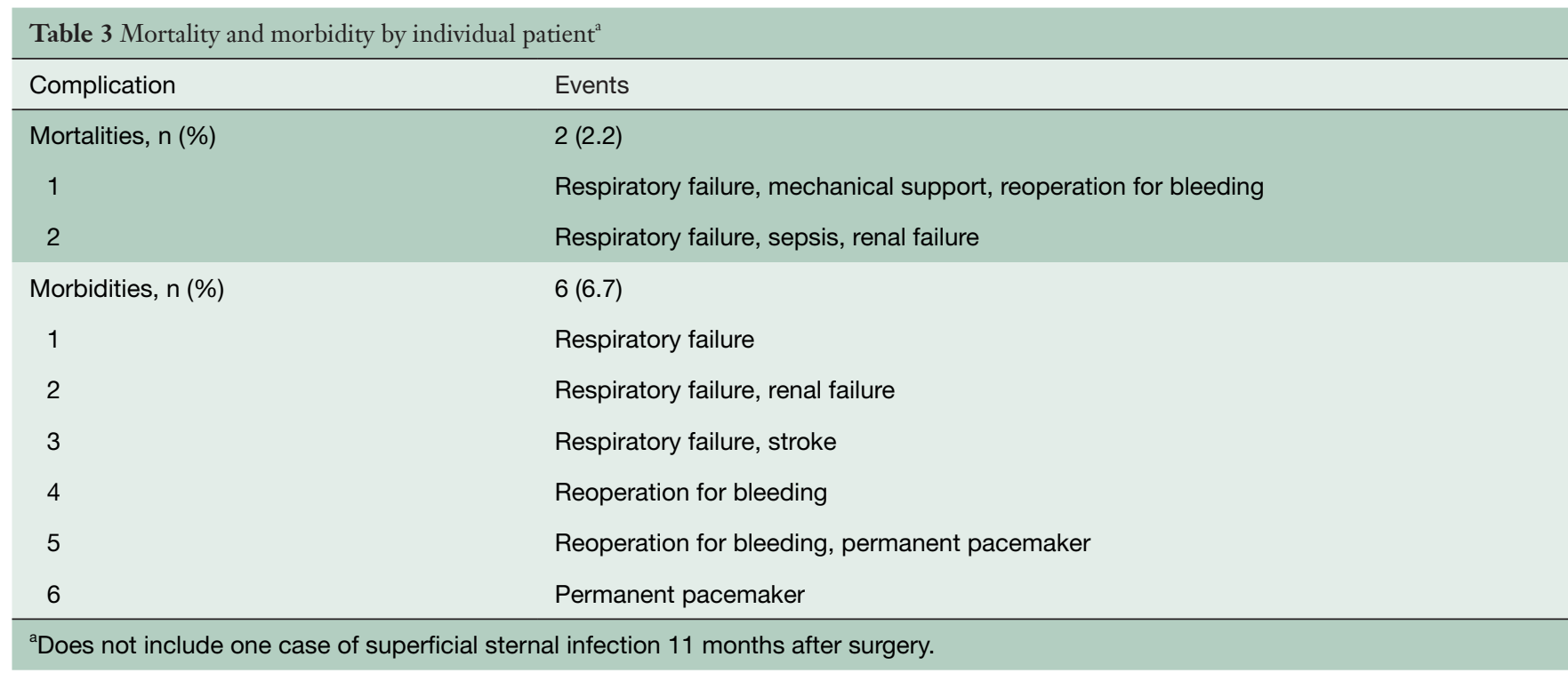



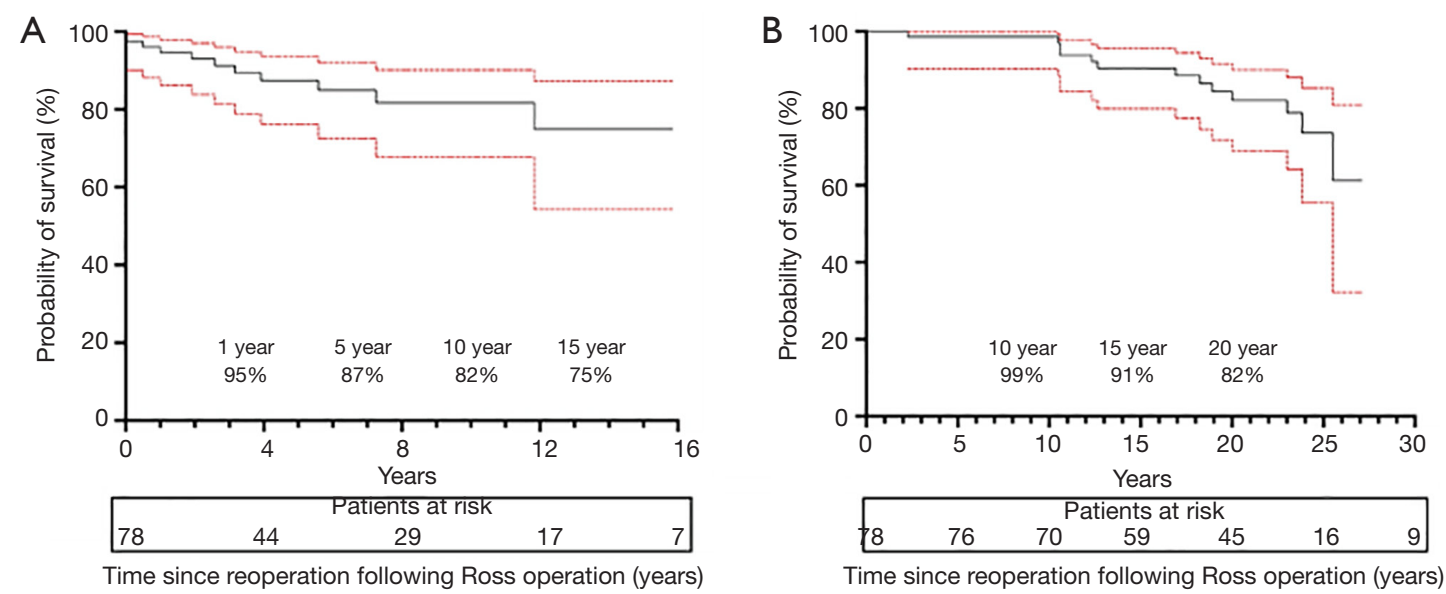

Figure 1 Kaplan-Meier survival curves with 95\% confidence intervals. (A) Survival after reoperation. (B) Survival after original Ross operation.

study, like the previous study from the Mayo Clinic (1), looks at the entire spectrum of reoperations that may be required after a Ross procedure. This will update clinicians to a more widely applicable risk analysis for reoperation, including experience in the most current decade. While the Mayo experience was marked by low immediate mortality, it reported considerable serious morbidity as well as additional mortality within just eight months of average follow-up. We also had low perioperative mortality — but also very low morbidity, as well as no deaths in the year following surgery. Our series also has the advantage of much longer follow-up.

\section{General observations-lessons learned}

\section{Autograft regurgitation}

$\mathrm{Neo-aortic}$ valve regurgitation was the most common problem requiring further surgery and was usually due to dilatation of the autograft root (Table 2). We anticipate that root support techniques will decrease this problem in the future. Importantly, stenosis of the autograft has never yet been seen which makes valve-in-valve catheter-based therapy impossible for the failed autograft with current technology.

We have learned that simple dilatation of the autograft sinuses (as large as $5.5 \mathrm{~cm}$ ) does not cause regurgitation if both the annulus and the sinotubular junction are stabilized. The root does not require replacement in this setting. Rupture of the autograft has never been reported to our knowledge. Dissection is extremely rare and the circumferential suture lines prevent propagation thereby protecting the coronaries, the valve, and the distal aorta. On the other hand, if aortic regurgitation becomes a problem, operating when it is moderate is more likely to allow valvesparing surgery instead of waiting for severe regurgitation. We have made every effort to preserve the living aortic valve but also chose replacement over a repair that we felt was unlikely to be durable.

A tissue valve was most often used when replacement was required. We made every effort to optimize hemodynamics and to make a valve-in-valve transcatheter aortic valve replacement (TAVR) possible in the future by using the largest valve size possible. If the root was not dilated, simple replacement was done. If the root was dilated, a Bentall operation was done. A stentless porcine root was often used in order to "upsize" the valve (Table 4).

\section{Homograft}

Stenosis was the driver of almost all homograft replacements (Table 5). Interestingly, in over two thirds of this series the homografts were found to be minimally calcified with excellent function and were left in place even though some of those were over twenty years old (Figure 2A). Percutaneous intervention (not included in this series) is now available but not always possible. For that reason, homografts with a peak gradient over $30 \mathrm{mmHg}$ should not be left behind if other lesions demand open surgical treatment. Importantly, right heart catheterization pressure measurements consistently show much lower homograft gradients than echocardiogram. When replacement is indicated, patient age, degree of homograft dysfunction, severity and distribution of calcification, and extent of other surgery are considered in making device choices. In the very 


\begin{tabular}{|c|c|}
\hline Category & Total $(n=176)$ \\
\hline Aortic & 86 \\
\hline Mechanical valve & 7 \\
\hline Tissue valve & 12 \\
\hline Stentless & 13 \\
\hline Homograft & 3 \\
\hline Valve sparing David & 5 \\
\hline Valve sparing Yacoub & 9 \\
\hline Valve repair & 6 \\
\hline Mechanical Bentall & 6 \\
\hline Biological Bentall & 9 \\
\hline Ascending aortic replacement & 16 \\
\hline Pulmonary & 27 \\
\hline Homograft & 17 \\
\hline Tissue valve + patch & 7 \\
\hline Freestyle & 1 \\
\hline Patch only & 2 \\
\hline Mitral & 24 \\
\hline Repair & 14 \\
\hline Replacement & 10 \\
\hline Tricuspid & 20 \\
\hline Repair & 19 \\
\hline Replacement & 1 \\
\hline \multicolumn{2}{|l|}{$\mathrm{CABG}^{\mathrm{a}}$} \\
\hline On-pump CABG & 5 \\
\hline \multicolumn{2}{|l|}{ Afib ablation ${ }^{\mathrm{b}}$} \\
\hline Cryo-Maze & 14 \\
\hline
\end{tabular}

\begin{tabular}{|ll}
\hline \multicolumn{2}{l}{ Table 5 Primary indications for reoperation } \\
\hline Operative indication & Total $(\mathrm{n}=89), \mathrm{n}[\%]$ \\
\hline Autograft & $36[40]$ \\
\hline Autograft and mitral & $9[10]$ \\
\hline Autograft and ascending aneurysm & $7[8]$ \\
\hline Homograft & $8[9]$ \\
\hline Homograft and mitral & $1[1]$ \\
\hline Both Ross valves & $11[12]$ \\
\hline Mitral & $8[9]$ \\
\hline Endocarditis & $5[6]$ \\
\hline Tricuspid & $2[2]$ \\
\hline Coronary & $2[2]$ \\
\hline
\end{tabular}

young patient and in older patients with severe calcification, a new homograft makes sense, preferably decellularized to decrease immune system response. Older patients may stand to benefit from a shorter operation and can keep a mildto-moderately dysfunctional homograft with the thought of catheter-based treatment if needed in the future. Tissue valves were often used in older patients with more limited calcification. A large stented tissue valve is implanted under a wide anterior patch from the right ventricular outflow tract to the main pulmonary artery.

\section{Aorta}

Ascending aortic aneurysm (other than the neo-root) can also occur on the basis of bicuspid aortopathy (Tables 4,5), but this has become less common over time, perhaps because of a more aggressive approach to the aorta at the original operation (9). When ascending aortic aneurysm is present, complete resection and circulatory arrest should be the standard approach, but sometimes the entirety of the pathology can be resected with the clamp on. In general, the space between the autograft and homograft roots should be left intact until the aorta is clamped to avoid injury to either structure. The space just over the native main pulmonary artery, under the junction of ascending aorta and transverse arch can usually be developed to the extent required for clamping. However, the presence of a previous hemi-arch replacement makes it more difficult to make room to clamp.

\section{Atrial fibrillation}

In the pursuit of avoiding anticoagulation, we included ablation procedures for atrial fibrillation in appropriate patients (Table 4), most often with concomitant mitral surgery. Resection or secure closure of the left atrial appendage was accomplished in most cases with atrial fibrillation.

\section{Insights gained}

\section{Pre-operative preparation}

One of the key concepts in making a reoperation safe is to anticipate the possibility at the first operation. Covering the great vessels with pericardium or pericardial substitute can be very helpful. A thorough operative note is best if given to the patient. Carefully gated arterial phase computed tomography angiography (CTA) of the chest is probably the most important preoperative imaging. It delineates the "mediastinal geography" in regard to sternal re-entry and usually gives enough information about the coronaries to avoid cardiac catheterization (Figures 2-4). 

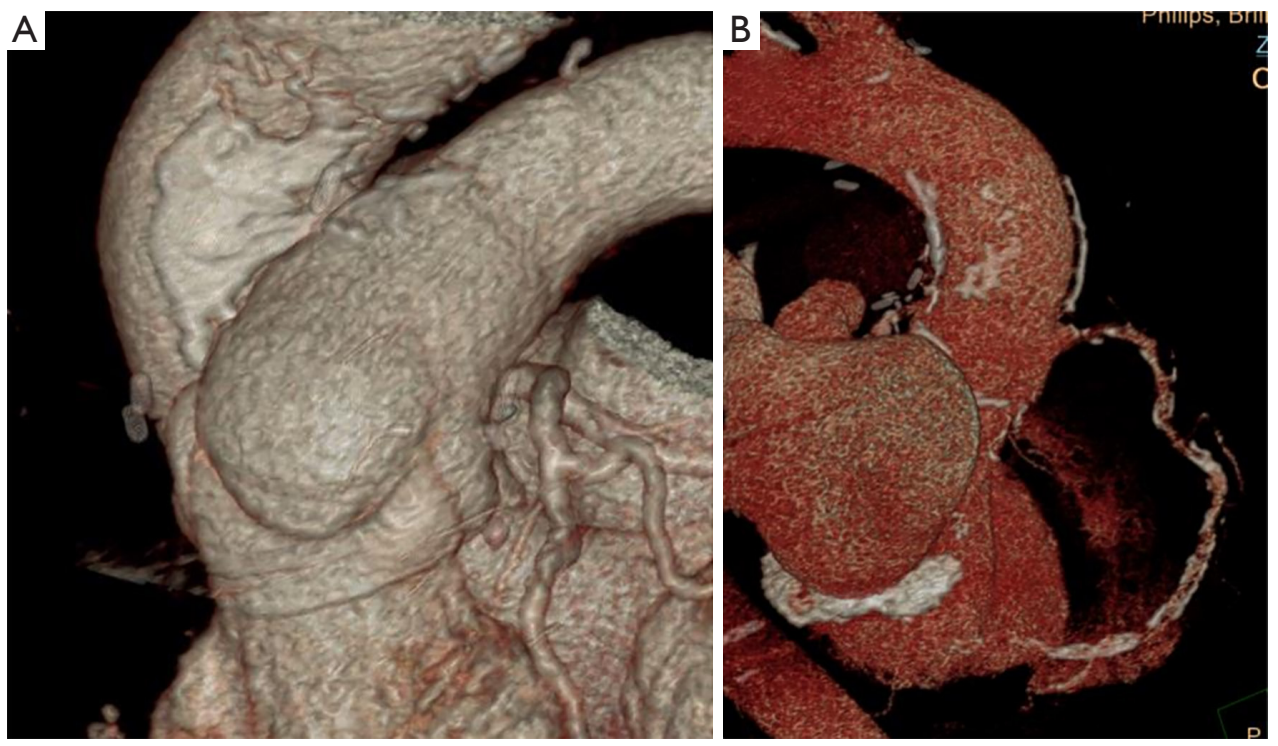

Figure 2 Aortas that should not be clamped. (A) Since mitral valve replacement was not possible safely without clamping, the aorta was replaced first under circulatory arrest and then the graft was clamped. Note the very normal looking homograft that was left alone as was the autograft (21 years post Ross). (B) This represents another aorta that was hostile as was the mitral annular calcification shown hereprocedures were performed on the fibrillating heart without clamping.
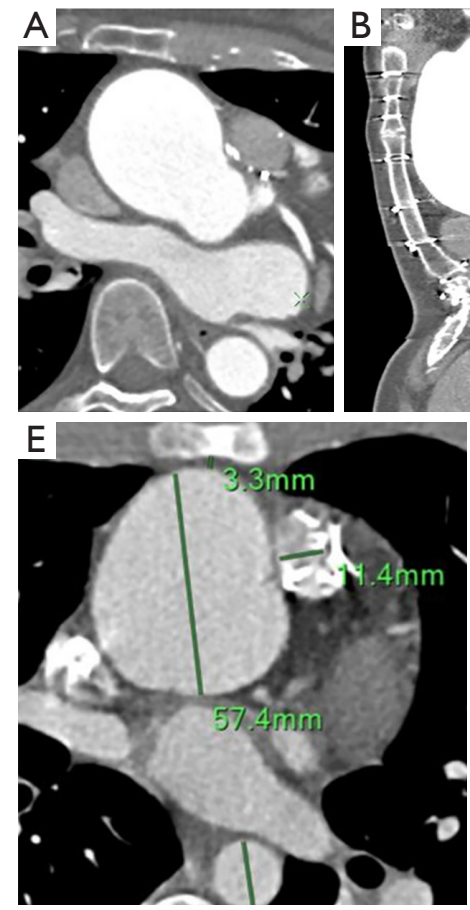
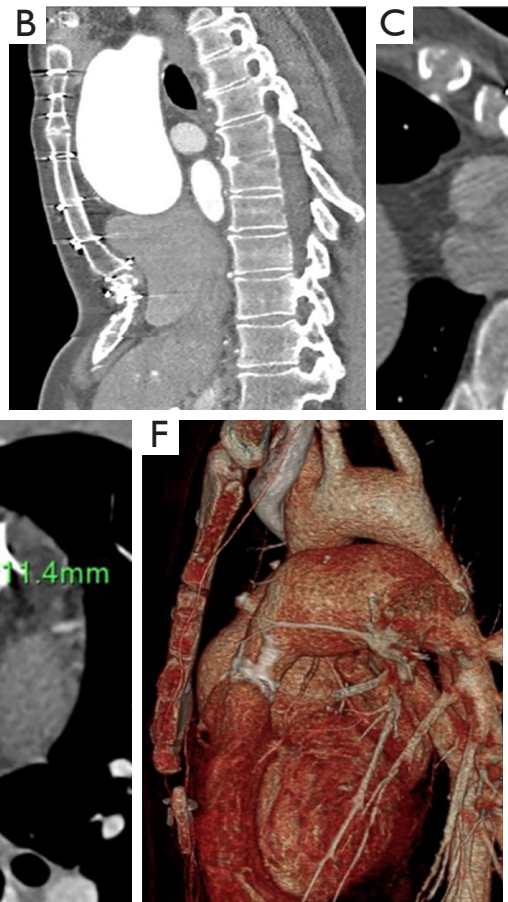
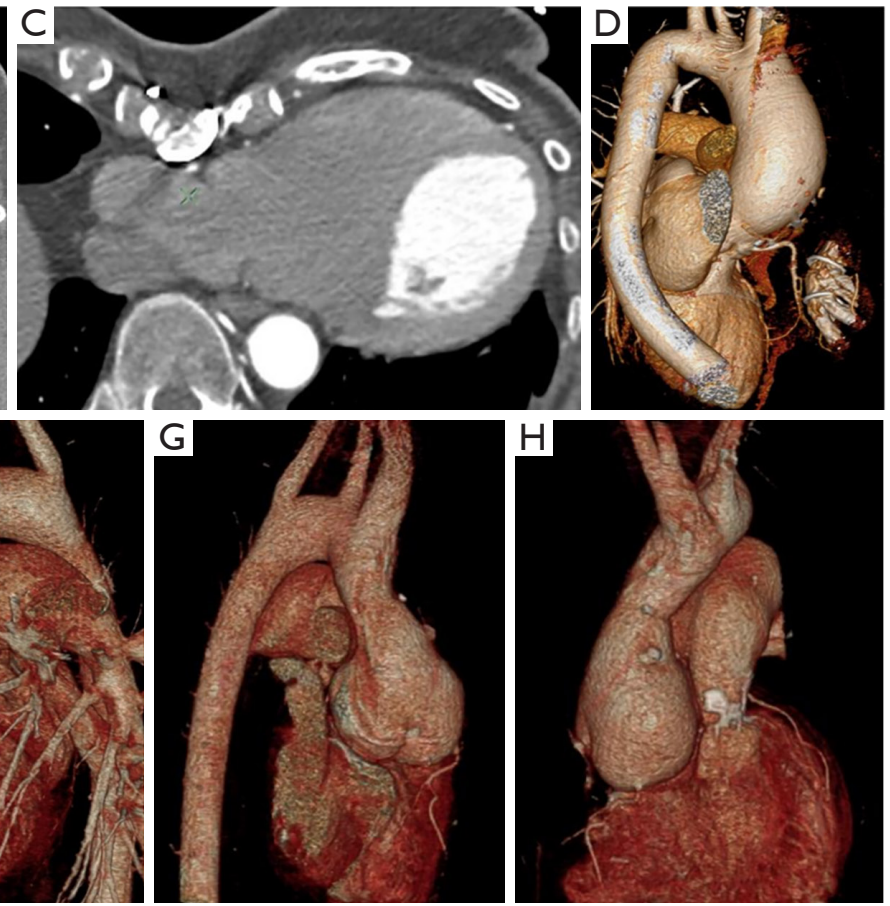

Figure 3 Images that triggered peripheral cannulation before sternotomy. (A,B,C,D) Patient with severe pectus deformity placing large right coronary in jeopardy. (E,F,G,H) Patient with aneurysmal autograft within one millimeter of sternum. Also seen is a calcified small pulmonary homograft 19 years after being implanted in a 1 year old. 

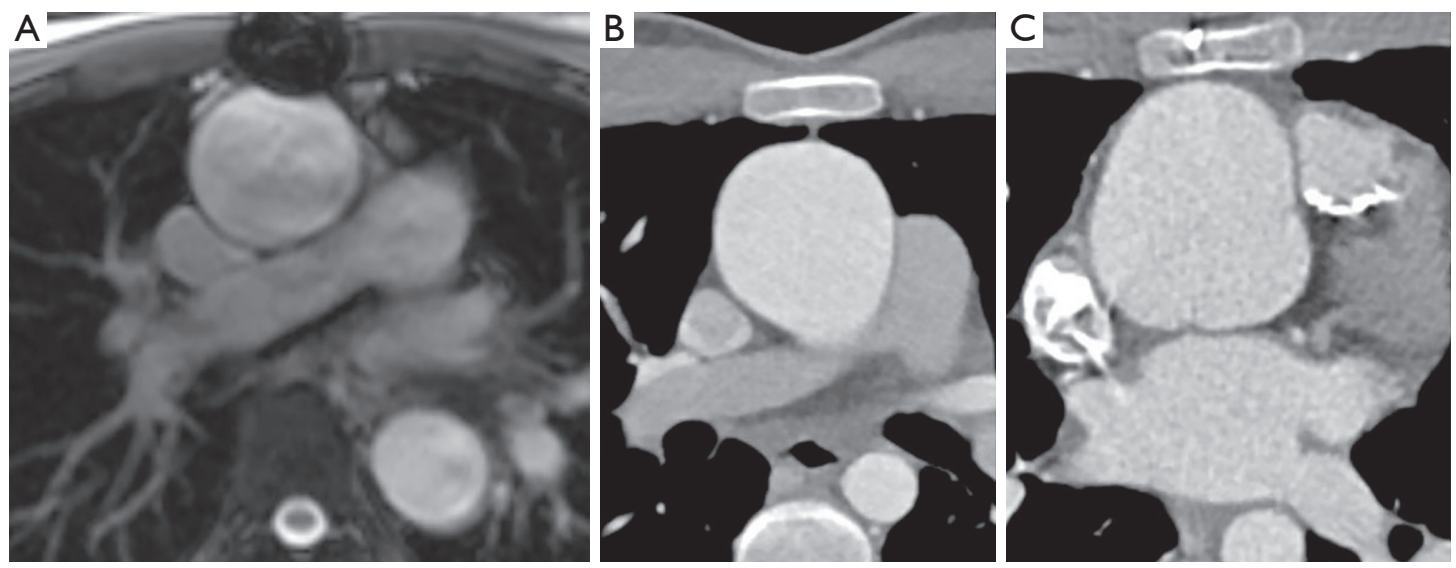

Figure 4 Magnetic resonance imaging (MRI) as compared to computed tomography angiography (CTA) for reoperative cardiac surgery. (A) "Halo" effect from sternal wires disguises space between sternum and aorta. (B) Same patient as assessed by CTA demonstrating the actual proximity of the aorta to the sternum, leading to a normal sternotomy. (C) CTA demonstrating significant proximity to the sternum, leading to peripheral cannulation and cooling prior to reoperative sternotomy.

An echocardiogram is obviously crucial. Transesophageal echocardiogram should be considered particularly with mitral pathology.

\section{Heart failure optimization}

Severe symptomatic heart failure with pulmonary hypertension makes pre-operative optimization extremely important to decrease fluid overload in both the lungs and the liver. This usually involves inpatient treatment with gentle inotropic therapy, usually phosphodiesterase inhibitor, and diuretic combination. Invasive assessment of pulmonary vascular resistance can be very helpful in determining the potential benefit of a planned mitral/tricuspid procedure in this setting and can clearly define any homograft pressure gradient. With the relief of a significant gradient serving to help a struggling right ventricle.

\section{Operative considerations}

On the basis of the CTA, we chose peripheral cannulation in only two patients (Figure 3). In general, we prepared the arterial circuit to allow switching to central cannulation when that exposure was safely ready. This allowed removal of the femoral arterial cannula to avoid distal ischemia. We used autologous normovolemic hemodilution whenever possible to preserve clotting factors to return after bypass. Right-sided procedures were occasionally done on a beating heart, but we preferred to do most things clamped with scrupulous myocardial protection. Some procedures were done without aortic clamping because of a "hostile" aorta (Figure 2). The aorta was always vented to prevent air embolization in those cases.

Time is clearly a factor in these cases, not just for the heart, but for the lungs, kidneys, liver, and brain. Both mortalities and most morbidity happened in cases that spent over four hours on cardiopulmonary bypass. Our experience would argue that strict attention to cardioplegia and meticulous technique can protect the heart for a long time and avoid major bleeding. However, the coagulation system is clearly weaker after four hours on the pump and blood bank products can be hard on the lungs. Nitric oxide can be very helpful, but it is not magic. The operative plan may need to be adjusted depending on the challenges met along the way. There must be a balance between doing what matters the most and doing everything possible.

Endocarditis presents unique challenges on many levels, but we were able to handle this even when both roots were involved.

\section{Clinical perspective}

This wide range of reoperative surgery (Table 4) in Ross patients has given a broad perspective on the pathology that can evolve over time not just in the two roots directly involved in the Ross procedure but also in the other valves and the aorta. Earlier intervention in more complex patients may prevent the development of severe pulmonary hypertension or left ventricular failure which increase risk. With careful preparation and scrupulous attention to surgical detail, these patients have consistently been able to return to the quality and quantity of life that we set out to offer them by doing the Ross procedure originally. 
Intuitively, the very good long-term survival of the Ross procedure may increase the chance of needing reoperation in the second and third decades but survival does not appear to be seriously affected by even multiple reoperations along the way (Figure $1 B$ ). Re-operative mortality and morbidity can be kept very low in an expert aortic center, especially one with considerable primary Ross experience.

\section{Strengths and limitations}

This is an observational, single-surgeon, retrospective study that comes with intrinsic selection bias and makes generalization difficult. There are important limitations inherent in this study design as in any case series. There was no control group for comparison and only descriptive statistics are appropriate in this setting. There is some very long-term follow-up providing valuable insights, but some of it is much shorter. The strength comes in the wide range of procedures in multiple different combinations that were done with a consistent surgical approach resulting in very low morbidity and mortality.

\section{Conclusions}

Reoperations after the Ross procedure can be required for many different pathologies, but all can be approached surgically with a high degree of safety in experienced hands. The very good long-term survival of Ross patients is not substantially altered by the need for reoperation. The potential need for further surgery should be discussed when offering a Ross in the first place, but it should not be used as a deterrent from getting the benefit of the Ross as our best option for non-repairable aortic valve disease in patients with life expectancy of at least fifteen years.

\section{Acknowledgments}

We thank Dr. Ismail El-Hamamsy for his extremely valuable advice on the editing of the manuscript. Funding: None.

\section{Footnote}

Conflicts of Interest: All authors have completed the ICMJE uniform disclosure form (available at https://dx.doi. org/10.21037/acs-2021-rp-29). The authors have no conflicts of interest to declare.

Open Access Statement: This is an Open Access article distributed in accordance with the Creative Commons Attribution-NonCommercial-NoDerivs 4.0 International License (CC BY-NC-ND 4.0), which permits the noncommercial replication and distribution of the article with the strict proviso that no changes or edits are made and the original work is properly cited (including links to both the formal publication through the relevant DOI and the license). See: https://creativecommons.org/licenses/by-nc-nd/4.0/.

\section{References}

1. Stulak JM, Burkhart HM, Sundt TM 3rd, et al. Spectrum and outcome of reoperations after the Ross procedure. Circulation 2010;122:1153-8.

2. Martin E, Mohammadi S, Jacques F, et al. Clinical Outcomes Following the Ross Procedure in Adults: A 25-Year Longitudinal Study. J Am Coll Cardiol 2017;70:1890-9.

3. Buratto E, Shi WY, Wynne R, et al. Improved Survival After the Ross Procedure Compared With Mechanical Aortic Valve Replacement. J Am Coll Cardiol 2018;71:1337-44.

4. Mazine A, Rocha RV, El-Hamamsy I, et al. Ross Procedure vs Mechanical Aortic Valve Replacement in Adults: A Systematic Review and Meta-analysis. JAMA Cardiol 2018;3:978-87.

5. Luciani GB, Lucchese G, De Rita F, et al. Reparative surgery of the pulmonary autograft: experience with Ross reoperations. Eur J Cardiothorac Surg 2012;41:1309-14; discussion 1314-5.

6. de Kerchove L, Boodhwani M, Etienne PY, et al. Preservation of the pulmonary autograft after failure of the Ross procedure. Eur J Cardiothorac Surg 2010;38:326-32.

7. Bekkers JA, Klieverik LM, Raap GB, et al. Aortic root reoperations after pulmonary autograft implantation. J Thorac Cardiovasc Surg 2010;140:S58-63; discussion S86-91.

8. Mookhoek A, de Kerchove L, El Khoury G, et al. European multicenter experience with valve-sparing reoperations after the Ross procedure. J Thorac Cardiovasc Surg 2015;150:1132-7.

9. Stelzer P, Mejia J, Varghese R. Operative risks of the Ross procedure. J Thorac Cardiovasc Surg 2021;161:905-915.e3.

Cite this article as: Stelzer P, Mejia J, Williams EE. Outcomes of reoperations after Ross procedure. Ann Cardiothorac Surg 2021;10(4):491-498. doi: 10.21037/acs-2021-rp-29 